\title{
Author Correction: Genus-wide sequencing support a two-locus model for sex-determination in Phoenix
}

\author{
Maria F. Torres ${ }^{1,2}$, Lisa S. Mathew ${ }^{3}$, Ikhlak Ahmed', Iman K. Al-Azwani ${ }^{3}$, Robert Krueger ${ }^{5}$, Diego Rivera-Nuñez ${ }^{6}$, \\ Yasmin A. Mohamoud ${ }^{3}$, Andrew G. Clark ${ }^{7}$, Karsten Suhre (i) ${ }^{4}$ \& Joel A. Malek (i) ${ }^{1,3}$
}

Correction to: Nature Communications; https://doi.org/10.1038/s41467-018-06375-y; published online 28 Sept 2018

In the original version of this Article, the affiliation of the first author, Maria F. Torres, 'Department of Biological Sciences, University of Cincinnati, Cincinnati, 45221, OH, USA' was incorrectly assigned as a present address and should have been listed as a full affiliation. This error has been corrected in both the PDF and HTML versions of the Article.

Published online: 03 December 2018

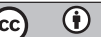

Open Access This article is licensed under a Creative Commons Attribution 4.0 International License, which permits use, sharing, adaptation, distribution and reproduction in any medium or format, as long as you give appropriate credit to the original author(s) and the source, provide a link to the Creative Commons license, and indicate if changes were made. The images or other third party material in this article are included in the article's Creative Commons license, unless indicated otherwise in a credit line to the material. If material is not included in the article's Creative Commons license and your intended use is not permitted by statutory regulation or exceeds the permitted use, you will need to obtain permission directly from the copyright holder. To view a copy of this license, visit http://creativecommons.org/licenses/by/4.0/.

(C) The Author(s) 2018

\footnotetext{
${ }^{1}$ Department of Genetic Medicine, Weill Cornell Medicine-Qatar, PO Box 24144Doha, Qatar. ${ }^{2}$ Department of Biological Sciences, University of Cincinnati, 45221 Cincinnati, OH, USA. ${ }^{3}$ Genomics Laboratory, Weill Cornell Medicine-Qatar, PO Box 24144Doha, Qatar. ${ }^{4}$ Department of Physiology and Biophysics, Weill Cornell Medicine-Qatar, PO Box 24144Doha, Qatar. ${ }^{5}$ USDA-ARS National Clonal Germplasm Repository for Citrus \& Dates, 92507 Riverside, CA, USA. ${ }^{6}$ Department of Plant Biology, Faculty of Biology, University of Murcia, 30100 Murcia, Spain. ${ }^{7}$ Department of Molecular Biology and Genetics, Cornell University, 14853 Ithaca, NY, USA. Correspondence and requests for materials should be addressed to J.A.M. (email: jom2042@qatar-med.cornell.edu)
} 